\title{
BMJ Open Changes in mortality inequalities across occupations in Japan: a national register based study of absolute and relative measures, 1980-2010
}

\author{
Hirokazu Tanaka, ${ }^{1,2}$ Satoshi Toyokawa, ${ }^{1}$ Nanako Tamiya, ${ }^{2}$ Hideto Takahashi, ${ }^{3}$ \\ Haruko Noguchi, ${ }^{4}$ Yasuki Kobayashi ${ }^{1}$
}

To cite: Tanaka H, Toyokawa S, Tamiya N, et al. Changes in mortality inequalities across occupations in Japan: a national register based study of absolute and relative measures, 1980-2010. BMJ Open 2017;7:e015764. doi:10.1136/ bmjopen-2016-015764

\section{- Prepublication history and} additional material for this paper are available online. To view these files please visit the journal online (http://dx.doi. org/10.1136/bmjopen-2016015764).

Received 30 December 2016 Revised 13 July 2017 Accepted 2 August 2017

\section{(a) CrossMark}

${ }^{1}$ Department of Public Health, Graduate School of Medicine, The University of Tokyo, Tokyo, Japan

${ }^{2}$ Department of Health Services Research, Faculty of Medicine, University of Tsukuba, Tsukuba, Japan

${ }^{3}$ Research Managing Director, National Institute of Public Health, Wako, Japan

${ }^{4}$ Faculty of Political Science and Economics, Waseda University, Tokyo, Japan

Correspondence to Hirokazu Tanaka;

htanaka@m.u-tokyo.ac.jp

\section{ABSTRACT}

Objective Changes in mortality inequalities across socioeconomic groups have been a substantial public health concern worldwide. We investigated changes in absolute/relative mortality inequalities across occupations, and the contribution of different diseases to inequalities in tandem with the restructuring of the Japanese economy.

Methods Using complete Japanese national death registries from 5 year intervals (1980-2010), all cause and cause specific age standardised mortality rates (ASMR per 100000 people standardised using the Japanese standard population in 1985, aged 30-59 years) across 12 occupations were computed. Absolute and relative inequalities were measured in ASMR differences (RDs) and ASMR ratios (RRs) among occupations in comparison with manufacturing workers (reference). We also estimated the changing contribution of different diseases by calculating the differences in ASMR change between 1995 and 2010 for occupations and reference.

Results All cause ASMRs tended to decrease in both sexes over the three decades except for male managers (increased by $71 \%$ points, 1995-2010). RDs across occupations were reduced for both sexes (civil servants 233.5 to -1.9 for men; sales workers 63.3 to 4.5 for women) but RRs increased for some occupations (professional workers 1.38 to 1.70; service workers 2.35 to 3.73 ) for men and decreased for women from 1980 to 2010 . Male relative inequalities widened among farmer, fishery and service workers, because the percentage declines were smaller in these occupations. Cerebrovascular disease and cancer were the main causes of the decrease in mortality inequalities among sexes but the incidence of suicide increased among men, thereby increasing sex related inequalities.

Conclusions Absolute inequality trends in mortality across occupations decreased in both sexes, while relative inequality trends were heterogeneous in Japan. The main drivers of narrowing and widening mortality inequalities were cerebrovascular disease and suicide, respectively. Future public health efforts will benefit from eliminating residual inequalities in mortality by considering the contribution of the causes of death and socioeconomic status stratification.

\section{Strengths and limitations of this study}

- All death counts in the study periods in Japan were included in this analysis using the anonymous individual death records provided by the Ministry of Health, Labour and Welfare, Japan.

- Analysis of mortality inequalities using both absolute and relative measures accurately described how mortality inequalities have changed over the three decades in Japan, thereby providing insights into how to eliminate residual inequalities in mortality worldwide.

- Studying mortality inequality in Japan provides unique opportunities to examine how prolonged stagnation affects population health across socioeconomic statuses, since Japan is considered to have the most efficient healthcare system worldwide with reduced health related inequalities.

- Although our data were derived from a national death registry, these data were individually unlinked to the national census; thus the identified occupations were the occupations of the deceased at the time of death.

\section{INTRODUCTION}

Reducing inequalities in health is one of the greatest challenges for public health. Before the Black Report, numerous studies have shown an inverse association between socioeconomic status and mortality in modern society, ${ }^{1}$ with occupation particularly being a main social determinant of health. ${ }^{2}$ Additionally, recent findings suggest that economic crises intricately affect health status and mortality through employment status and occupation. ${ }^{3}$

Regarding monitoring progress towards the reduction or elimination of health inequalities, previous studies have discussed both absolute and relative measures to investigate changes in mortality inequalities, ${ }^{4}$ since relative measure analysis (the type most commonly reported in health inequalities ${ }^{6}$ ) 
can be misleading. ${ }^{7}$ For instance, a widening in relative inequalities in mortality is commonly observed in European countries, even if absolute inequalities between high and low socioeconomic status groups are narrowing. ${ }^{8}$ Although both larger absolute and larger relative declines in high mortality socioeconomic status groups are desirable for eliminating inequalities, an absolute decline in each group is valuable for eliminating excessive mortality.

Therefore, tracking national changes in both absolute and relative mortality inequalities would aid in the evaluation of past efforts and identify residual gaps in challenges for public health. Nevertheless, such studies are infrequent in Japan. ${ }^{9}$ Furthermore, it is not known how different diseases contribute to mortality inequalities along with recent changes in Japanese society, although these observations have been reported for European countries $^{1011}$ and elsewhere. ${ }^{12}$ Japan is believed to have less inequality in health; unquestionably, Japan has the most effective population health system worldwide. ${ }^{13}$ However, studies have suggested that relative inequality in health across socioeconomic statuses at the municipal and occupational level have widened over three decades, and are associated with premature death. ${ }^{14}$ After the collapse of the 'bubble economy' in the first half of the 1990s, Japan's economy underwent a long recession until the 2010s. This period of prolonged recession included the 2008 global economic crisis and is termed the 'lost two decades'. Consequently, the unemployment rate and the proportion of non-regular workers increased gradually, and the recent Japanese labour market is characterised by organisational streamlining, including downsizing, that results in an increase in male individual working hours. ${ }^{16}$ These changes and the impact of the 1997 Asian financial economic crisis caused rapid increases in mortality among middle aged male professional/management workers in the late 1990s. ${ }^{17}$ Moreover, previous studies have found that the trend was different from the inverse association between socioeconomic status and mortality. ${ }^{17}$ Thus we hypothesised that changes in mortality inequalities in Japan and the contribution of different diseases may be different from what has been observed in Western countries.

Within this context, we investigated whether absolute and relative inequalities between occupation and all cause mortality have changed using the national death registry, which includes all death events in the Japanese population. Furthermore, we estimated the changing contribution of different diseases to these inequalities in tandem with the restructuring of the Japanese economy.

\section{METHODS}

\section{Study design}

A repeated cross sectional study was conducted using government records from the National Vital Statistics (for death records) and the Population Census data (for the population count) of Japan from 1980 to $2010 .{ }^{18}$ We used all cause and cause specific mortality in 1980, 1985,
1990, 1995, 2000, 2005 and 2010 as outcome measures, which were stratified per occupation. Age, sex and cause specific death counts (numerator) were derived from nationwide individual death records while the population exposures (denominator) were obtained from the Population Census. This way, our analysis estimated mortality across occupations using the repeated cross sectional data setting. The identified occupations used in this study were determined based on the occupations of the deceased at the time of death (not necessarily the occupations in which individuals were mainly engaged throughout their lifetime).

\section{Data sources}

We obtained 6384651 individual data points in the form of death certificates from the National Vital Statistics with occupational and industrial data in Japan from 1980 to 2010. The Ministry of Health, Labour and Welfare (MHLW) has conducted this survey every 5 years since 1970, coinciding with the years of the Population Census. Every survey period lasts for 12 months of the fiscal year (from 1 April of the survey year to 31 March of the next year) in Japan. ${ }^{18}$ MHLW approved the secondary use of the data by MHLW\#1218-1.

In the case of death (numerator; from 1 April of the survey year to 31 March of the next year), the family of the person who had died was asked to fill in the occupation of the deceased at the time of death, as well as his or her industry groups. To calculate mortality across occupations, we obtained age and sex aggregated population census data for occupation specific populations (denominator; the mid-year population estimates) from the Japanese Population Census, which is conducted in 5 year intervals on 1 October.

\section{Occupation}

Occupation and industry categories used in this survey were the Japan Standard Occupational Classification and the Japan Standard Industrial Classification, respectively. ${ }^{18} 19$ These are also used in the Population Census. To analyse detailed occupation and enhance the generalisability of this study, we additionally used data for individual industries. This was an important perspective for elucidating the socioeconomic status related risk factors as well as occupation. ${ }^{20}$ We categorised 12 types of occupations using the combination of occupation and industry group. Table 1 shows these definitions. For women, we aggregated manager, security official, construction, transport and fisheries, and added these categories to 'other' because of the relatively small population (approximately less than 200000 people, which is less than approximately $1.0 \%$ of working women). Therefore, we excluded 'other' from the calculation of mortality since 'other' was included in the mixed occupational groups and is not comparable.

\section{Outcome}

Data on death certificates, including the underlying cause of death, were completed by physicians who 


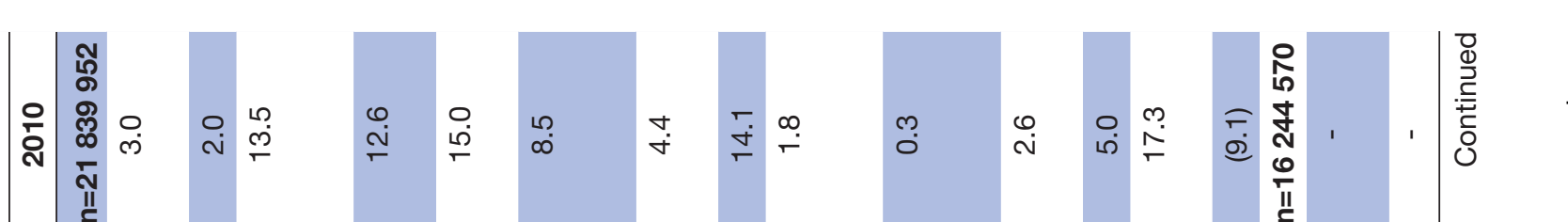

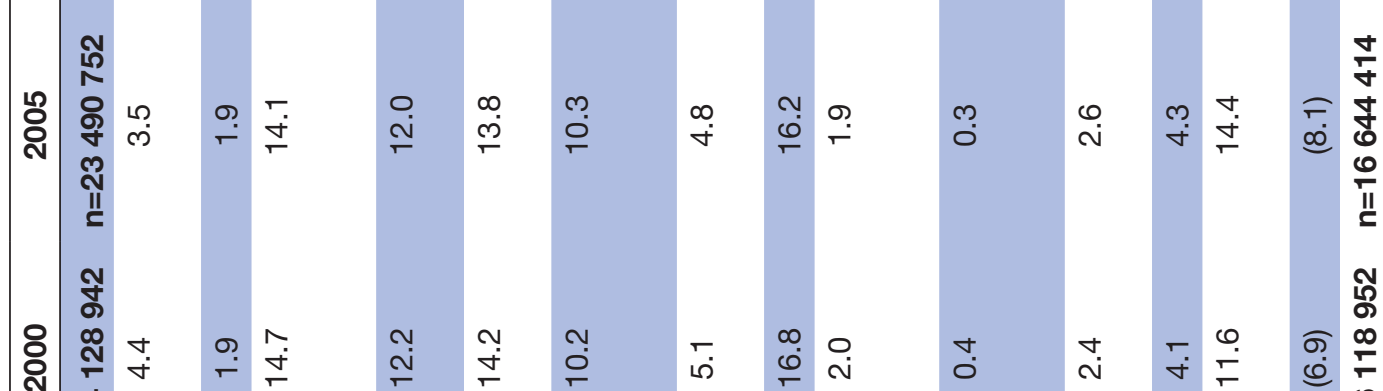

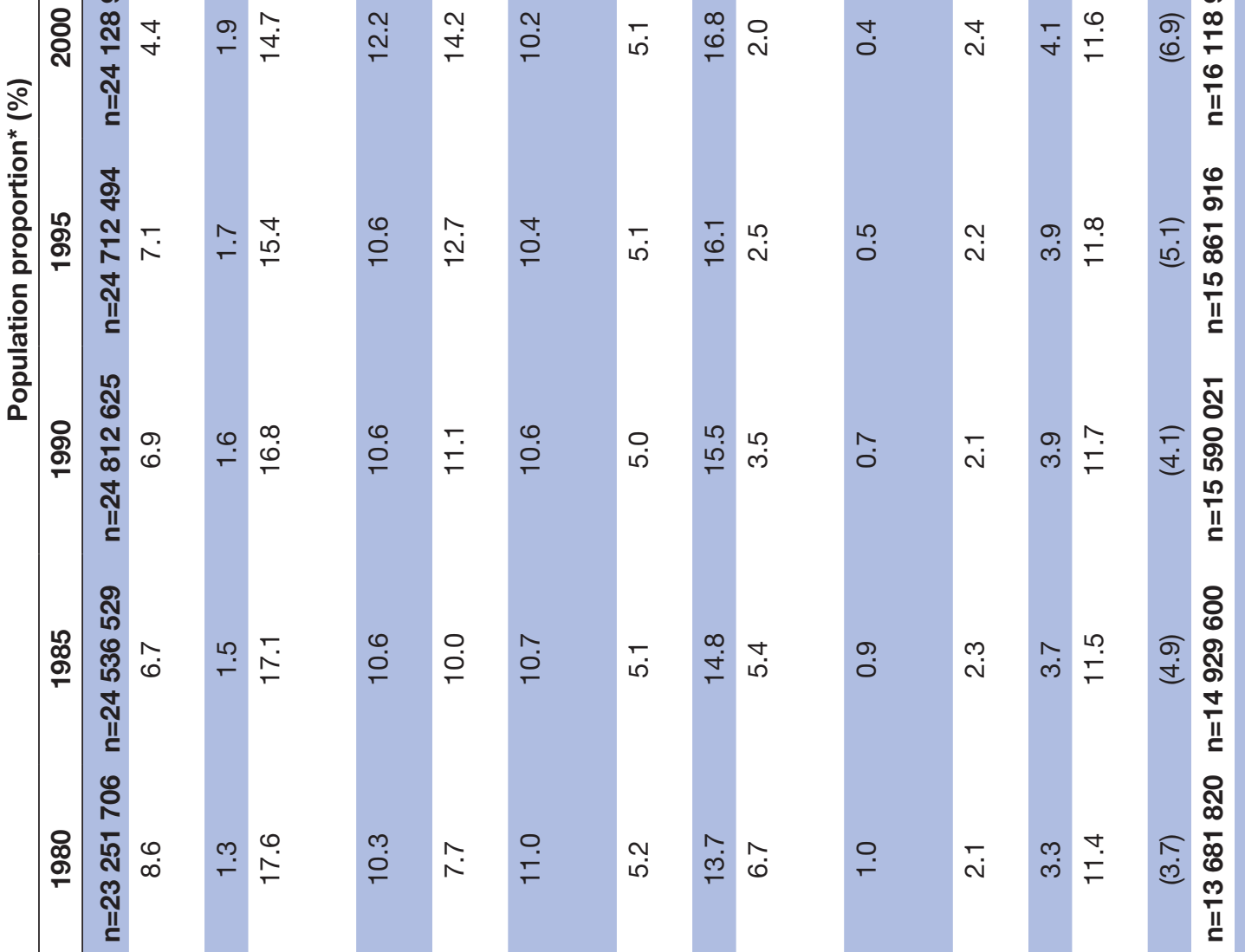

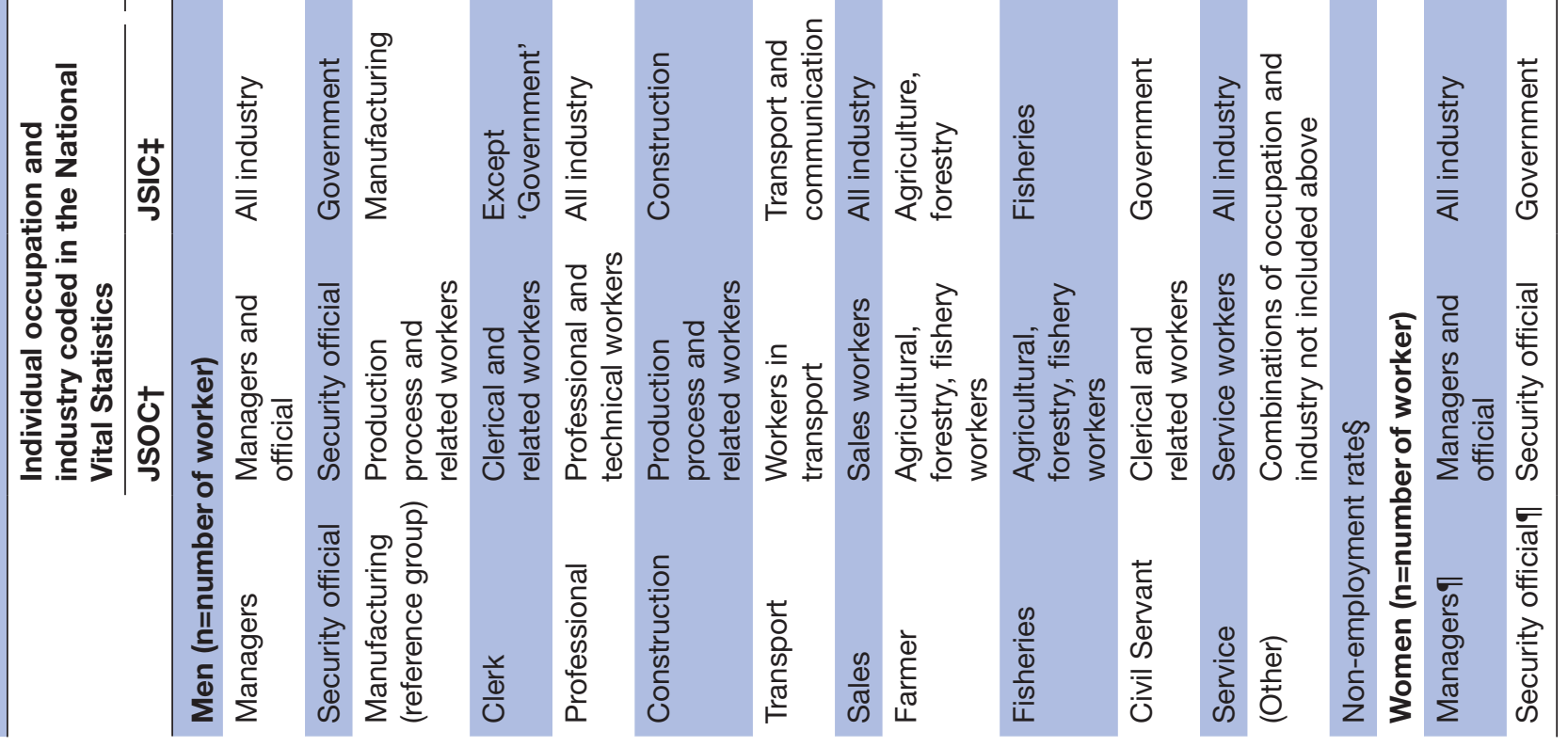




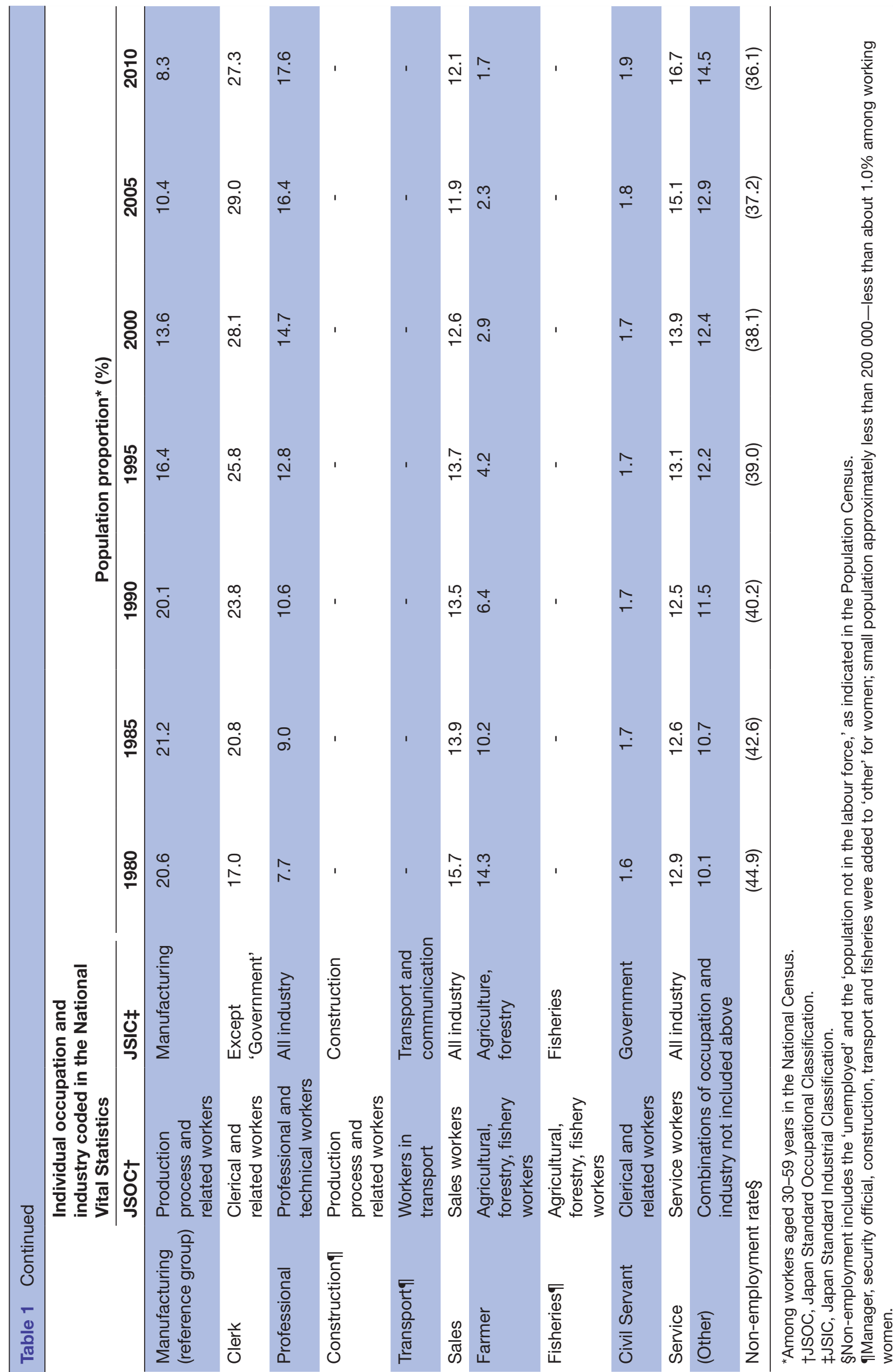


diagnosed death or examined the corpse post mortem. Cause of death was based on the sequence of morbid events leading to death and coded according to the International Statistical Classification of Diseases and Related Health Problems ninth revision (in 1980, 1985, 1990) and $10^{\text {th }}$ revision (in $1995,2000,2005,2010$ ), hereafter referred to as ICD-9 and ICD-10, respectively.

\section{Analysis}

We restricted the analysis to workers who were aged 30-59 years. Workers aged $\geq 60$ years were excluded because 60 years was the typical retirement age in Japan during the study period. We also excluded workers aged 15-29 years because this age band includes high school, university and other higher education students. All analyses were conducted by sex. With data based on a 5 year age interval, age standardised mortality rates (ASMRs) were computed per 100000 people and directly standardised with the Japanese standard population in 1985, which is commonly used in demographic descriptions to compare health statistics across different years in Japan. To analyse changes in mortality rate patterns across occupation, we computed all cause ASMRs from 1980 to 2010 and ASMR differences (RDs) in comparison with the manufacturing group (reference group) as absolute measures. ASMR ratios (RRs) across occupation to manufacturing workers were computed to reveal relative inequalities in mortality, respectively, in 1980, 1995 and 2010, as relative measures. To focus on Japanese social changes, we divided individuals into sub-periods (ie, 1980-1995 and 1995-2010) since a previous study reported dramatic mortality pattern changes across occupations and a rapid increase in the suicide rate in the late 1990s. ${ }^{17}$ Manufacturing was chosen as the reference group because it constituted the majority of the population among both sexes and it has tended to be the lowest group of ASMR throughout our study period.

We focused on the contribution of the cause of death to changes in absolute inequalities. The differences across occupations in comparison with manufacturing in cause specific ASMR difference from 1980 to 1995, and from 1995 to 2010, respectively, were computed. The causes of death included: common cancer (ICD10; C16, C18-C21, C22, C91-C95), other neoplasms (C00-C99, D00-D48 excluding 'common cancer' and C32-C34), ischaemic heart diseases (I20-I25), cerebrovascular diseases (I60-I69), smoking related causes (C32-C34, J40-J44, J47), alcohol related causes (E24.4, F10, G31.2, G62.1, G72.1, I42.6, K29.2, K70, K85.2, K86.0, R78.0, X45, Y15), road traffic accidents (V01V89, Y85) and suicide (X60-X84). The gold standard is the information on the cause of death from vital registration; however, a potential bias could be attributable to the inclusion of ill defined codes (such as heart failure) and unknown causes. With the algorithm developed by Naghavi et al, ill defined codes and unknown causes on death certificates were redistributed to be comparable across data ${ }^{21}$ (see online supplementary appendix table 1 regarding the above classification and redistributed codes by ICD-9 and ICD-10). We used Stata V.14.1 (StataCorp, College Station, Texas, USA) to perform statistical analyses and manage data.

\section{RESULTS}

\section{All cause mortality and number of deaths}

Table 2 shows all cause ASMR trends and the number of deaths among Japanese people aged $30-59$ years by sex. All cause ASMR decreased in both sexes in 1980-1995 and 1995-2010: $-24 \%$ and $-13 \%$ points for men, and $-27 \%$ and $-13 \%$ points for women (all population), respectively. For workers, all cause ASMR also decreased in both sexes in $1980-1995$ and $1995-2010$ : $-36 \%$ and $-38 \%$ points for men, and $-42 \%$ and $-35 \%$ points for women, respectively. Non-employment ASMRs were much higher than those for workers. All cause ASMR for men was nearly twofold that for women among this age group in Japan.

The number of deaths has been decreasing for both sexes since 1985 for men and since 1980 for women. The percentage of non-classifiable workers or missing values (no responses about occupation) increased from $4.1 \%$ to $17.5 \%$ for men and from $2.1 \%$ to $15.1 \%$ for women from 1980 to 2010.

\section{Changes in inequalities in all cause mortality—absolute and relative measures}

Table 3 shows ASMR trends across occupations. Apart from male managers, the trend in all cause ASMR generally decreased in both sexes: $-70 \%$ points for male civil servants, $-12 \%$ points for male fisheries, $-51 \%$ points for female civil servants and $-12 \%$ points for female manufacturing, 1995-2010. Although the ASMR for male managers was lowest in 1980, it was ranked as the fourth highest among 12 types of occupation in 2010, and only increased by $71 \%$ points over the study period (1995-2010).

Figure $1 \mathrm{~A}$ and $\mathrm{B}$ shows the inequality pattern changes in RDs (see online supplementary appendix table 2, which provides RD data for every survey period). The decline in absolute mortality inequalities (ie, RDs per 100000 people) were especially large among civil servants (233.5 to -1.9 for men, 137.8 to 15.7 for women), clerks (63.7 to -12.7 for men, 21.9 to -5.7 for women) and sales (141.8 to 0.4 for men, 63.3 to 4.5 ) for both sexes from 1980 to 2010 , but the RD widened in male managers (19.0 to 162.7) from 1995 to 2010. Female absolute mortality inequalities across occupations appeared to be eliminated after 1995, except for farmers.

Figure $1 \mathrm{C}$ and $\mathrm{D}$ shows that male RRs increased in managers (0.85 to 3.04 ), professionals (1.38 to 1.70 ), farmers (2.07 to 3.14), fisheries (2.12 to 3.57) and services (2.34 to 3.73) from 1980 to 2010 , but declined among civil servants (2.19 to 0.98 ) and sales (1.72 to 1.01). Female RRs generally became less unequal from 1980 to 2010, except for female farmers (see online supplementary 
Table 2 Trends in age standardised mortality rates and number of death among Japanese population aged 30-59 years

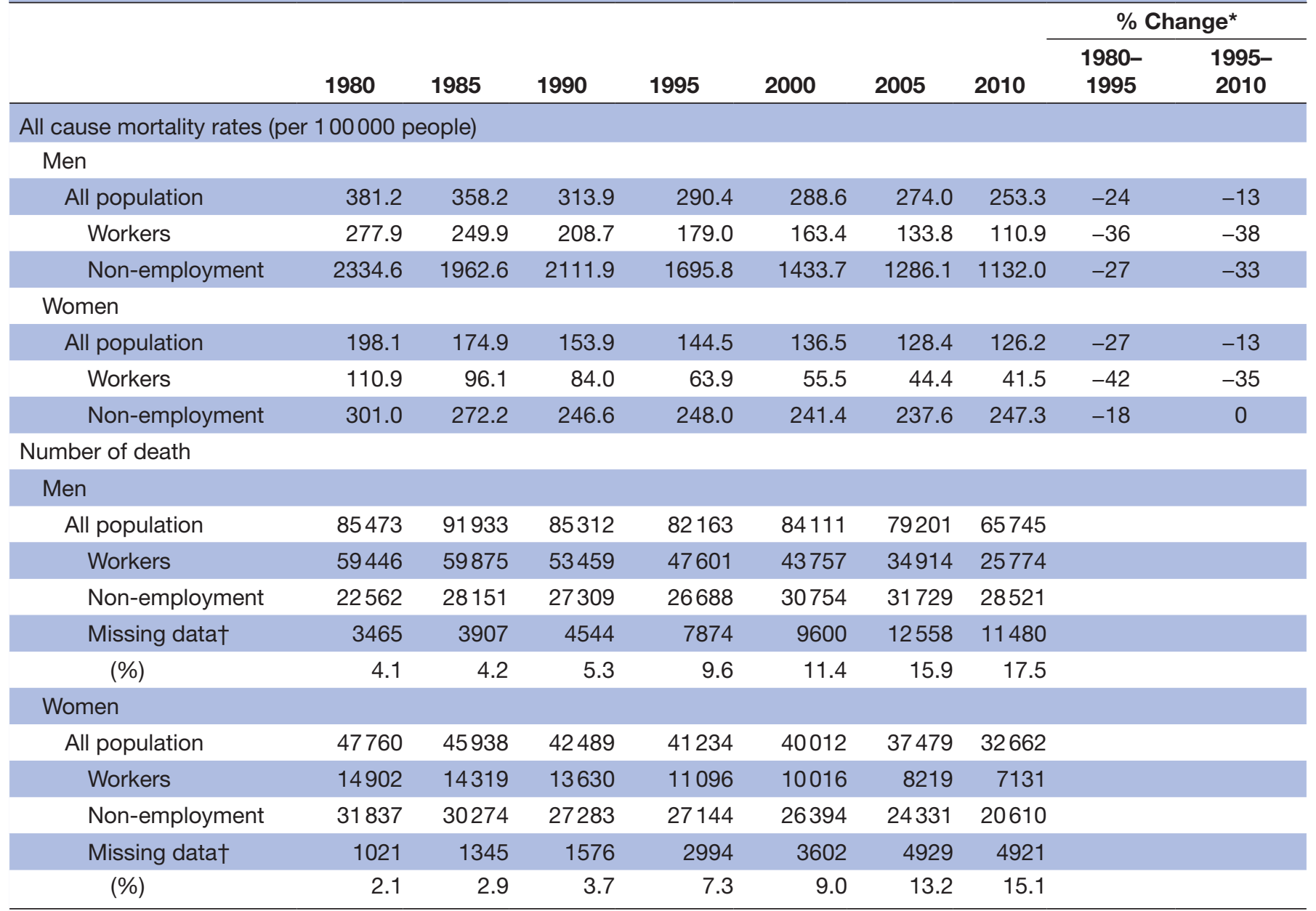

*Difference rates expressed as percentages of the 1980 and 1995 rates.

†Missing data means the percentage of not classifiable workers or missing value (no responses about occupation), which were excluded from the occupation specific mortality calculation: all population deaths is the sum of deaths of workers, non-employment and missing data.

appendix table 3, which provides RR data for every survey period).

\section{Changes in inequalities in cause specific mortality—absolute measures}

Figure 2 shows the contribution of the cause of death to changes in absolute inequalities between each occupation and manufacturing (see also online supplementary appendix figure 1). Cerebrovascular disease mainly contributed to declining absolute inequalities across occupations for both sexes from 1980 to 1995, but suicide and road traffic accidents contributed to widening inequality, particularly among men in transport, farmer, fisheries and service categories. Cancer, road traffic accidents and cerebrovascular disease mainly contributed to declining absolute inequalities for both sexes from 1995 to 2010, but suicide has still contributed to the widening inequality for men. Hence suicide has been the main contributor to the widening of the mortality inequalities for manager, professional, farmer, fisheries and service for men over the three decades.

\section{DISCUSSION}

Main findings

We empirically showed that absolute inequalities have decreased across occupations, but relative inequalities have increased in some occupations for men, which is compatible with a report from European countries and New Zealand. ${ }^{4}$ When we collated these results, male relative inequalities in mortality widened among farmer, fishery and service workers, because the percentage declines were smaller in these occupations. Female mortality inequalities across occupation were lower than those for men (table 3, figure 1). Narrowing of absolute inequalities across occupation was mainly driven by substantial progress in reducing mortality from cerebrovascular disease (1980-2010) and cancer (1995-2010) for both sexes; however, our results point to an important contribution of mortality from suicide to the widening inequalities in mortality since 1980 for men (figure 2). In comparison with international public health trends, the main driver of narrowing or widening mortality inequalities was different from that which was observed in 


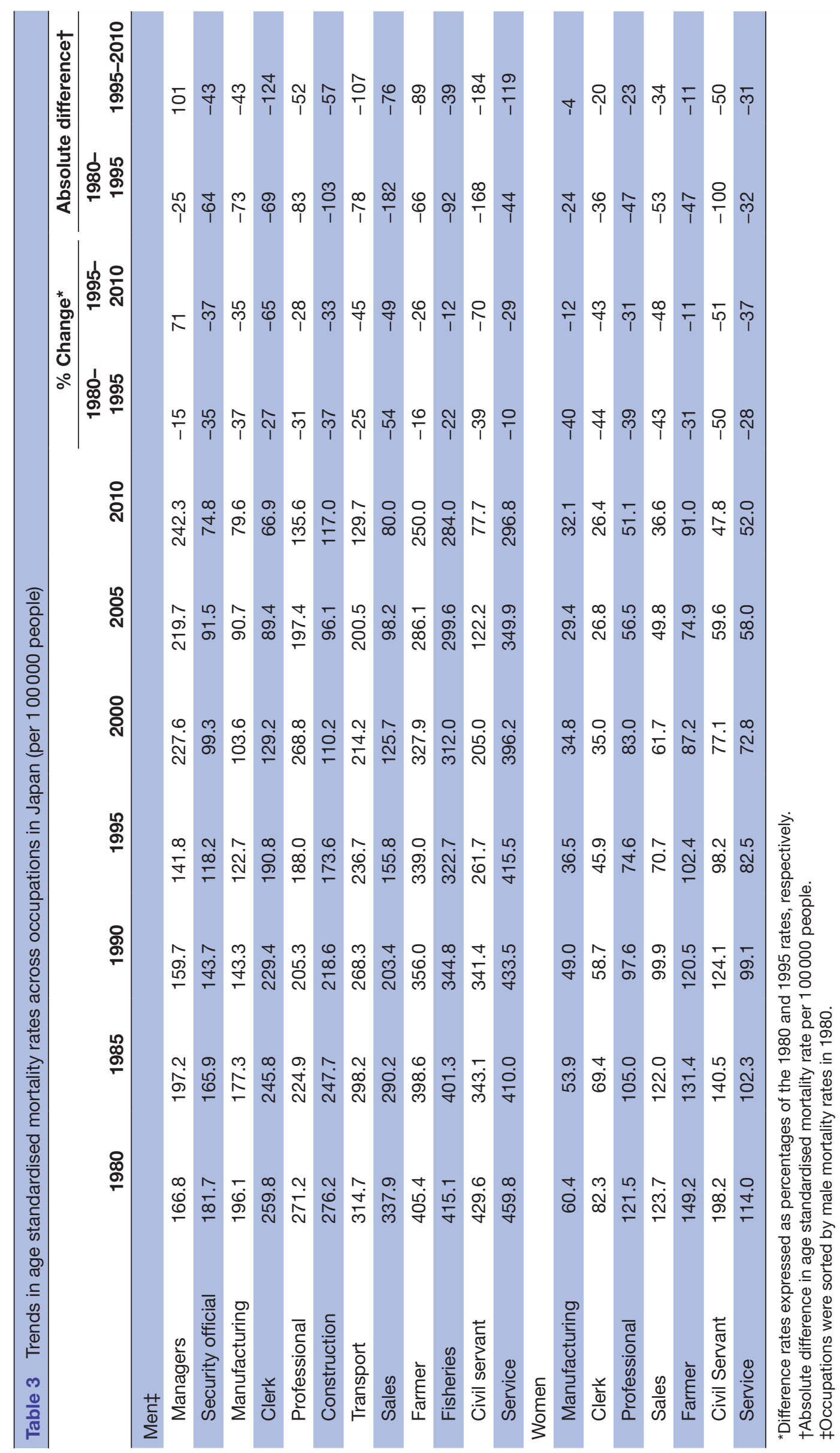


(A) Men: absolute measures

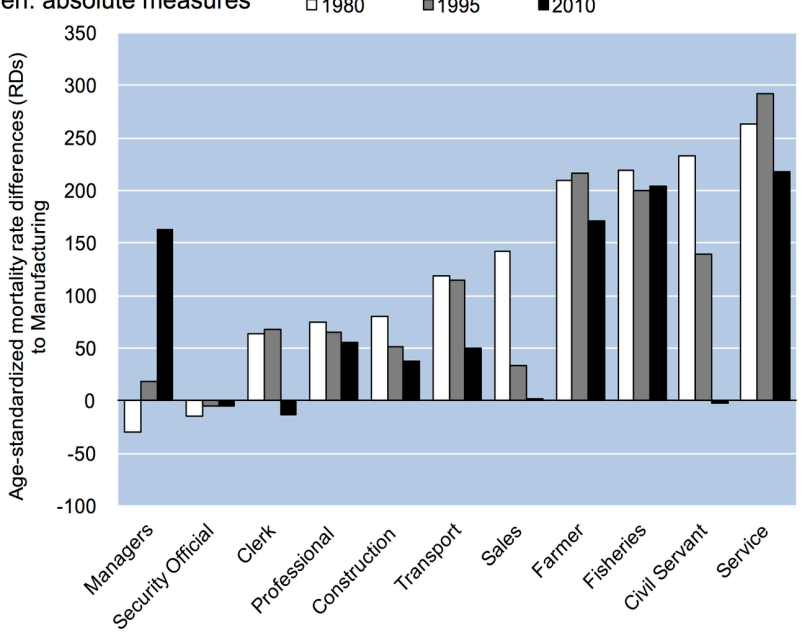

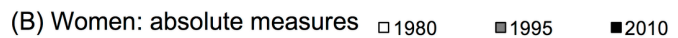

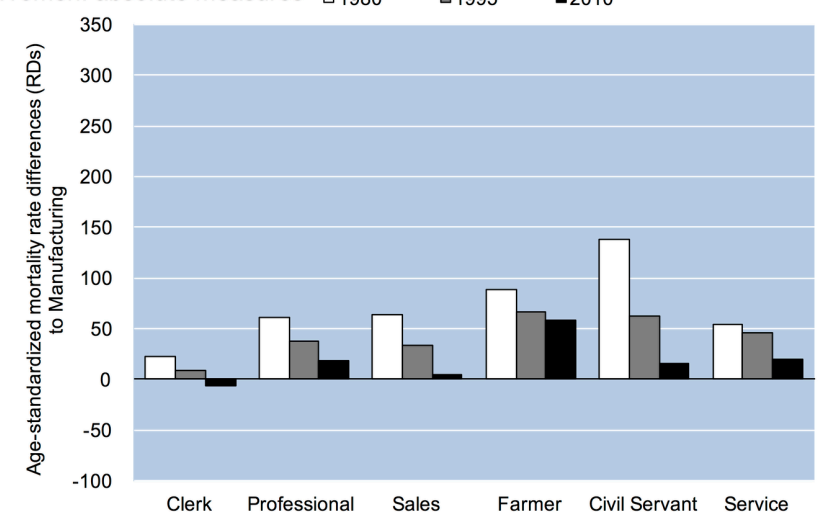

(C) Men: relative measures

$\square 1980$

$\square 1995$

- 2010

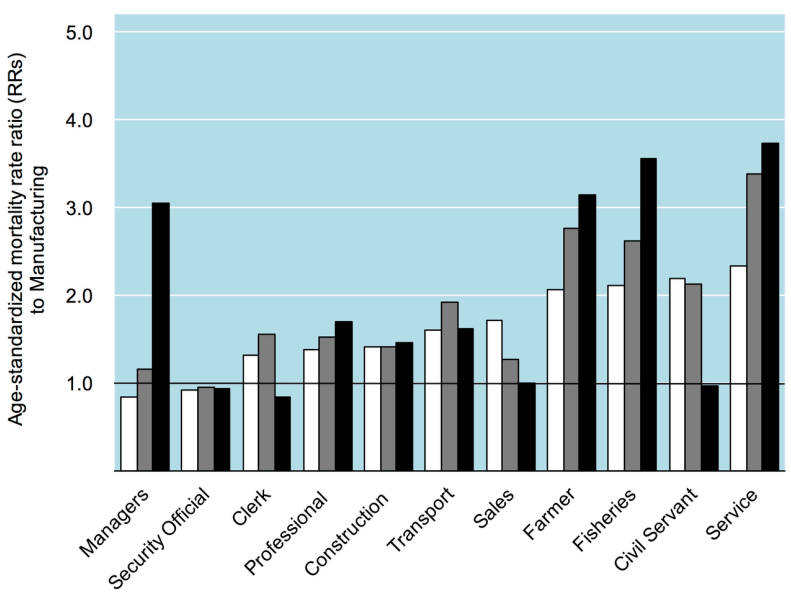

(D) Women: relative measures $\quad \square 1980 \quad \square 1995 \quad \mathbf{Q} 2010$

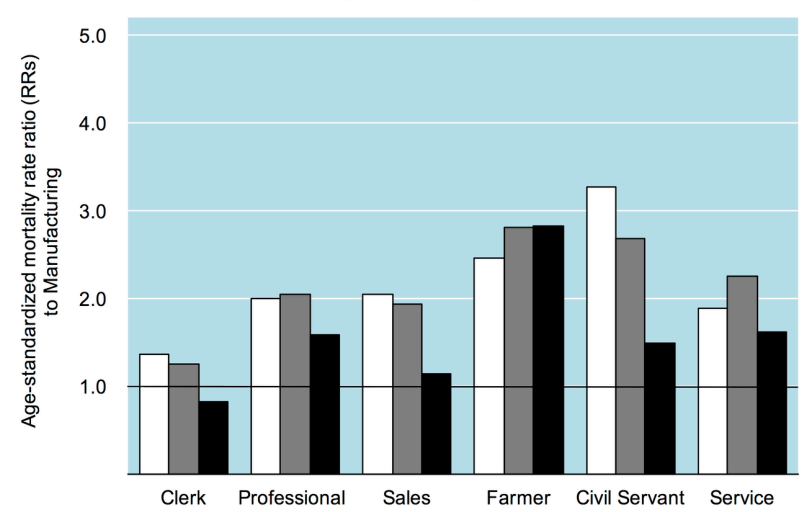

Figure 1 Changes in mortality rate differences (RDs) (A, B) and the mortality rate ratios (RRs) (C, D) across occupations in comparison with manufacturing among Japanese aged 30-59years, from 1980 to 2010: absolute and relative measures, respectively.

European countries, where ischaemic heart disease and smoking related causes were indicated. ${ }^{1011}$

This work substantially advances previous research in mortality inequalities concluded from Japanese nationwide vital registry analysis for both sexes, including absolute and relative measures, detailed occupations and analysis of contribution of cause specific death. Although 'flat and lower' bars indicate the elimination of mortality inequalities (figure 1), excess death has been observed for some occupations, such as male managers, farmers and service workers. These residual gaps in mortality inequalities across occupation are challenges for public health in Japan (see also online supplementary appendix table 4 regarding the STROBE statement).

\section{Interpretation}

Regarding an international comparison of the structure of diseases, Asian populations have a relatively higher risk of stroke and a lower risk of ischaemic heart disease than Western populations. ${ }^{22}$ Therefore, public health efforts in Japan have been mainly focused on cerebrovascular disease, such as stroke, over the past half century. Hence a considerable reduction has been achieved in mortality due to cerebrovascular disease, mainly because of the increase in insurance coverage of antihypertensive drugs among hypertension patients and improvements in lifestyle, including reduced dietary salt intake. ${ }^{13}$ Additionally, since cancer has been the leading cause of death since 1981 in Japan, the Cancer Control Act was approved in 2006 to reduce cancer mortality through prevention and treatment standardisation..$^{23}$ It appears that the reductions in absolute inequalities in mortality of cerebrovascular disease and cancer across occupation are a byproduct of population wide improvements in favourable behaviour changes and advances in prevention and treatment. Our findings suggest that past public health efforts and nationwide improvements in quality of medical care have reduced inequality in socioeconomic status over three decades in Japan.

There were, however, substantial setbacks for reducing absolute inequalities that were due to suicide in men. Suicide has been a main public health concern in Japan, especially during the recent recession. ${ }^{13}$ The suicide rate in Japan has been one of the highest worldwide: about three times higher than that in the UK (24.62 in Japan vs 8.45 in the UK per 100000 population, summarised in 2007).${ }^{24}$ Our finding also suggests that the suicide rate increased among managers, farmers, fisheries and service workers and resulted in weakening in the reduction of 


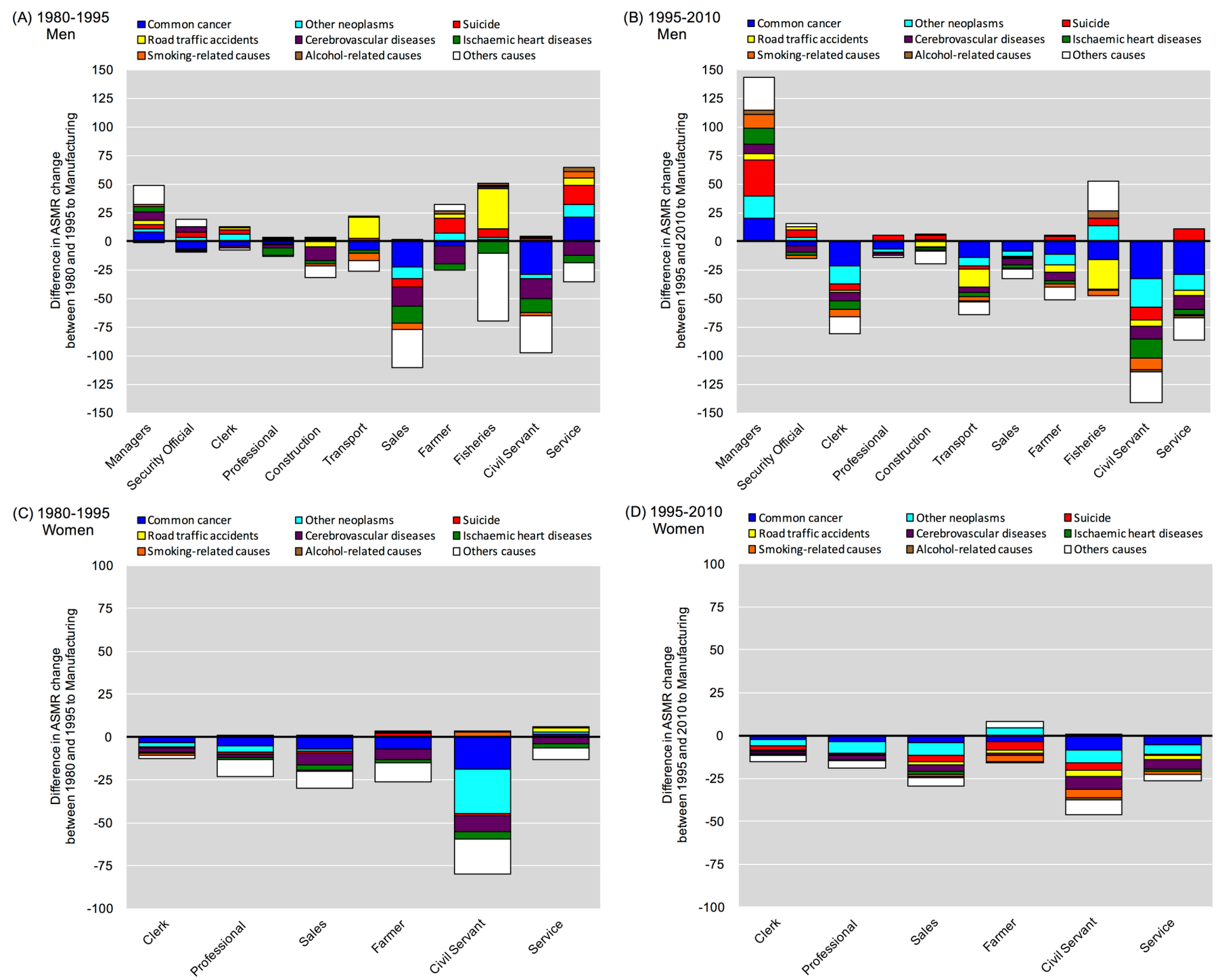

Figure 2 Contribution of cause specific death to changes in absolute inequalities between each occupation and manufacturing during 1980-1995 (A, C) and 1995-2010 (B, D). Differences in changes in ASMR between 1995 and 2010 were calculated as $\left.\left(A_{S M R} M_{210}-A_{S M R}\right)_{1995}\right)-\left(A_{S M R}\right.$ 2010-manufacturing $\left.-A S_{1995-m a n u f a c t u r i n g}\right)$ for each cause specific death, where $A S M R=a g e$ standardised mortality rate per 100000 population.

absolute all cause mortality rate, causing an increase in the relative mortality inequalities for men over three decades. Suicide has been shown, in part, to contribute to the widening of mortality inequalities in tandem with an economic slow down in high suicide rate countries, such as Korea ${ }^{25}$ while suicide has not contributed to the widening of mortality inequalities in European countries due to an absolutely low suicide rate. ${ }^{10}$ However, suicide is a potential contributor to increasing mortality inequalities worldwide, because recent studies have discussed associations between the 2008 global economic crisis and suicide. ${ }^{26}$ For example, suicide rates have been increasing among working age white non-Hispanic Americans and Greeks, coinciding with the financial crisis or austerity measures, respectively. ${ }^{27} 28$ These empirical facts indicate the importance of suicide prevention for reducing mortality inequalities, especially when sudden macroeconomic conditions change.
Road traffic accidents contributed to widening mortality inequalities in 1980-1995, but there was a reduction in 1995-2010 for men. The rate of road traffic fatalities has decreased since 1992, coinciding with the start of the recent recession in Japan. ${ }^{29}$ Therefore, our results point to an important contribution of mortality inequality trends for male transport workers wherein there are high occupational risks of road traffic accidents. Our findings suggest that economic booms or downturns may cause a widening or reduction in mortality inequalities, respectively, since the cyclicality of road mortality for the economy is generally symmetric. ${ }^{30}$ Advances in the prevention of road traffic accidents are key in mediating the narrowing of inequalities in mortality, especially in developing countries with generally high road traffic mortality during economic booms. ${ }^{29}$

Here we applied high socioeconomic status referencing theory based socioeconomic classification (the Japanese 
Socioeconomic Classification (J-SEC) derived from a classification based on the National Statistics Socioeconomic Classification in the UK) to managers and professional workers. ${ }^{31}$ In the J-SEC framework, all workers categorised as manager and professional workers were classified as the highest class in terms of socioeconomic status. We found that high grade-manager and professionalworker mortality was higher than in other occupations that are generally described as middle class, such as civil servant, clerk and sales workers in modern Japanese society. Such phenomena have rarely been observed in Western countries, ${ }^{10}$ but may be compatible with a report from Korea. ${ }^{32}$ There are unique patterns in occupational health gradients in Japan, which derive from high job demands and strong pressures on high grade workers, as discussed by Wada et al. ${ }^{17}$ Although high grade workers, such as managers, generally have much discretion, this cannot be applied in Japan. Japanese managers, during a recent recession, have often been described as 'a player manager,' wherein they formerly were high performing employees but lost decision making discretion and encountered greater psychological demand in tandem with the company downsizing. ${ }^{16}$ This demonstrates that Karoshi (death from overwork, including suicide) ${ }^{33}$ which is the most serious occupational health topic in Japan, is a complex health problem related to recent Japanese social changes in work environments and employment systems. Alternatively, these working and health conditions appear to influence the responsibilities of young professionals in tandem with the restructuring of the Japanese economy. In witnessing the stop of Japan's strong economic growth after the 'bubble economy' collapsed and the heavy burdens placed on high grade workers, many young Japanese, particularly the well educated, were the first to recognise that they will no longer be better off than their parents. Hence we suspect 'low risk occupations' with stable employment against recession, such as clerk and civil servant, have become popular for the well educated middle aged Japanese, while other occupations, such as farmer, fishery and service workers, may still be perceived as high risk and burdensome occupations. In the modern Japanese society, a unique vertical form of stratification may have been established. In this way, a collapse in traditional working culture may produce unique effects on health inequalities.

\section{Limitations}

Some limitations should be noted. First, although our data were derived from a national death registry, these data were individually unlinked to the national census; thus, the identified occupations indicated the occupations of the deceased at the time of death. Some occupation mortality may be underestimated as occupations may have been reported as 'unemployed' or as another occupation since an individual may have changed or lost their job after having a serious illness. Second, those occupations in which employment status is commonly described as self-employed, including various categories, may be overestimated. Third, there was an increase in missing data regarding occupations for both sexes in this dataset, especially since the mid-1990s (see table 2). This might reflect the increase in non-regular and/or unstable jobs because of a long recession in Japan as well as the increase in single individuals who did not have any family member who was asked to fill in his/her occupation at the time of his/her death in Japan. Moreover, there was an increase in the percentage of non-classifiable workers ('other') or 'not stated' occupations in the Population Census (denominator) in tandem with recent complications of occupational classification. These increases in missing data and non-classifiable occupations may distort our analysis. Fourth, the Japan Standard Occupational Classification and the Japan Standard Industrial Classification were revised in several instances during the study period. This led to a misclassification of occupations that distorted the trend analysis. These data should thus be interpreted with caution. Fifth, we failed to define detailed associations between occupation and socioeconomic status. Although we assumed managers and professional workers were the highest class in applying the J-SEC, ${ }^{28}$ the occupations we defined may not reflect socioeconomic status correctly. Finally, our analysis included only middle aged (30-59years) men and women, which indicates that the many deaths that occur in other working age groups were not included. Therefore, sex comparisons (magnitude of mortality across each occupation by sex) should be interpreted with caution in this data set. Individual linkage between the National Vital Statistics and the Population Census data will be expected in the future to overcome these limitations in Japan.

\section{CONCLUSIONS}

Absolute inequalities in mortality across occupations have decreased for both sexes, while relative inequality trends were heterogeneous. These changes in mortality inequalities across occupation in Japan were driven by substantial progress in reducing the mortality from cerebrovascular disease and cancer for both sexes; however, there were substantial setbacks for reducing mortality due largely to suicide in men. Reducing inequalities in mortality critically depends on speeding up mortality declines among high mortality occupations. Future public health efforts will benefit from eliminating residual inequalities in mortality by considering the contribution of the causes of death and socioeconomic status stratification.

Contributors HT had full access to all study data and was responsible for data integrity, the accuracy of data analysis and drafting the manuscript. HT, ST and YK contributed to the concept and design of the study. NT, HT, HN and YK acquired the data and obtained funding. HT, ST and YK were responsible for data analysis and interpretation, while HT and ST conducted the statistical analysis. All authors critically reviewed the manuscript. NT and YK also supervised the study and provided administrative, technical and material support.

Funding This study was supported by the Ministry of Health, Labour and Welfare (H27-seisaku-senryaku-012). The funder had no role in the design and conduct of the study; collection, management, analysis and interpretation of the data; 
preparation, review or approval of the manuscript; and decision to submit the manuscript for publication.

Competing interests None declared.

Ethics approval The study was approved by the research ethics committee of the Graduate School of Medicine, The University of Tokyo (approval No. 11038) and the research ethics committee of the Graduate School of Medicine, University of Tsukuba (approval No. 1009).

Provenance and peer review Not commissioned; externally peer reviewed. Data sharing statement No additional data available.

Open Access This is an Open Access article distributed in accordance with the Creative Commons Attribution Non Commercial (CC BY-NC 4.0) license, which permits others to distribute, remix, adapt, build upon this work non-commercially, and license their derivative works on different terms, provided the original work is properly cited and the use is non-commercial. See: http://creativecommons.org/ licenses/by-nc/4.0/

(C) Article author(s) (or their employer(s) unless otherwise stated in the text of the article) 2017. All rights reserved. No commercial use is permitted unless otherwise expressly granted.

\section{REFERENCES}

1. Macintyre S. The black report and beyond: what are the issues? Soc Sci Med 1997;44:723-45.

2. Marmot M. Social determinants of health inequalities. Lancet 2005;365:1099-104.

3. Glonti K, Gordeev VS, Goryakin Y, et al. A systematic review on health resilience to economic crises. PLoS One 2015;10:e0123117.

4. Mackenbach JP, Kulhánová I, Menvielle G, et al. Trends in inequalities in premature mortality: a study of 3.2 million deaths in 13 European countries. J Epidemiol Community Health 2015;69:207-17.

5. Blakely T, Tobias M, Atkinson J. Inequalities in mortality during and after restructuring of the New Zealand economy: repeated cohort studies. BMJ 2008;336:371-5.

6. King NB, Harper S, Young ME. Use of relative and absolute effect measures in reporting health inequalities: structured review. BMJ 2012;345:e5774.

7. Mackenbach JP. The persistence of health inequalities in modern welfare states: the explanation of a paradox. Soc Sci Med 2012;75:761-9.

8. Mackenbach JP, Martikainen P, Menvielle G, et al. The arithmetic of reducing relative and absolute inequalities in health: a theoretical analysis illustrated with European mortality data. J Epidemiol Community Health 2016;70:730-6.

9. Kagamimori S, Gaina A, Nasermoaddeli A. Socioeconomic status and health in the Japanese population. Soc Sci Med 2009;68:2152-60.

10. Mackenbach JP, Kulhánová I, Artnik B, et al. Changes in mortality inequalities over two decades: register based study of European countries. BMJ 2016;353:i1732.

11. Renard F, Gadeyne S, Devleesschauwer B, et al. Trends in educational inequalities in premature mortality in Belgium between the 1990s and the 2000s: the contribution of specific causes of deaths. J Epidemiol Community Health 2017;71:371-80.

12. Fawcett J, Blakely T. Cancer is overtaking cardiovascular disease as the main driver of socioeconomic inequalities in mortality: New Zealand (1981-99). J Epidemiol Community Health 2007;61:59-66.
13. Ikeda N, Saito E, Kondo N, et al. What has made the population of Japan healthy? Lancet 2011;378:1094-105.

14. Suzuki E, Kashima S, Kawachi I, et al. Social and geographic inequalities in premature adult mortality in Japan: a multilevel observational study from 1970 to 2005. BMJ Open 2012;2:e000425.

15. Kondo N, Subramanian SV, Kawachi I, et al. Economic recession and health inequalities in Japan: analysis with a national sample, 19862001. J Epidemiol Community Health 2008;62:869-75.

16. Genda Y, Kuroda S, Ohta S. Does downsizing take a toll on retained staff? An analysis of increased working hours in the early 2000 s in Japan. J Jpn Int Econ 2015;36:1-24.

17. Wada K, Kondo N, Gilmour S, et al. Trends in cause specific mortality across occupations in Japanese men of working age during period of economic stagnation, 1980-2005: retrospective cohort study. BMJ 2012;344:e1191.

18. Ministry of Health Labour and Welfare. Report of vital statistics: occupational and industrial aspects. http:www.mhlw.go.jp/english/ database/db-hw/orvf.html

19. Ministry of Internal Affairs and Communications. Establishing and improving statistical standards. http://www.soumu.go.jp/english/ dgpp_ss/seido/123.htm

20. Mannetje A, Kromhout $\mathrm{H}$. The use of occupation and industry classifications in general population studies. Int $J$ Epidemiol 2003;32:419-28.

21. Naghavi M, Makela S, Foreman K, et al. Algorithms for enhancing public health utility of national causes-of-death data. Popul Health Metr 2010;8:9.

22. Kim AS, Johnston SC. Global variation in the relative burden of stroke and ischemic heart disease. Circulation 2011;124:314-23.

23. Ministry of Health Labour and Welfare. Health and medical services. 2012 http://www.mhlw.go.jp/english/wp/wp-hw6/dl/02e.pdf

24. Jacob KS, Sharan P, Mirza I, et al. Mental health systems in countries: where are we now? Lancet 2007;370:1061-77.

25. Chan $\mathrm{CH}$, Caine ED, You S, et al. Suicide rates among working-age adults in South Korea before and after the 2008 economic crisis. J Epidemiol Community Health 2014;68:246-52.

26. Chang SS, Stuckler D, Yip P, et al. Impact of 2008 global economic crisis on suicide: time trend study in 54 countries. BMJ 2013;347:f5239.

27. Case A, Deaton A. Rising morbidity and mortality in midlife among white non-Hispanic Americans in the 21st century. Proc Natl Acad Sci U S A 2015;112:15078-83.

28. Rachiotis G, Stuckler D, McKee M, et al. What has happened to suicides during the Greek economic crisis? Findings from an ecological study of suicides and their determinants (2003-2012). BMJ Open 2015;5:e007295.

29. World Health Organization. 2009. Global status report on road safety: time for action. http://www.who.int/violence_injury prevention/road_safety_status/report/cover_and_front_matter_en. pdf

30. Chen G. Association between economic fluctuations and road mortality in OECD countries. Eur J Public Health 2014;24:612-4.

31. Hiyoshi A, Fukuda Y, Shipley MJ, et al. A new theory-based social classification in Japan and its validation using historically collected information. Soc Sci Med 2013;87:84-92.

32. Lee HE, Kim HR, Chung YK, et al. Mortality rates by occupation in Korea: a nationwide, 13-year follow-up study. Occup Environ Med 2016;73:329-35.

33. Kondo N, Oh J. Suicide and karoshi (death from overwork) during the recent economic crises in Japan: the impacts, mechanisms and political responses. J Epidemiol Community Health 2010;64:649-50. 